\title{
Renal Manifestation in Patients with Primary Hyperparathyroidism: a Retrospective Analysis in a Tertiary Institute

\author{
${ }^{1}$ Shamim M F Begum, ${ }^{1}$ Nasreen Sultana, ${ }^{1}$ Rahima Parveen, ${ }^{2}$ Khaled Bin Shamsuddin, ${ }^{3}$ Md Bashir, ${ }^{1}$ Layla S Banu \\ ${ }^{1}$ National Institute of Nuclear Medicine \& allied Sciences(NINMAS), BSMMU, Dhaka, Bangladesh \\ ${ }^{2}$ Medical Officer, Directorate General of Health Services, Dhaka \\ ${ }^{3}$ Dhaka Medical Collage Hospital, Dhaka
}

Correspondence Address: Dr. Shamim Momtaz Ferdousi Begum, Professor and Head, Scintigraphy Division, NINMAS, BSM

Medical University, Dhaka, Bangladesh, email:pragyna06@yahoo.com

\section{ABSTRACT}

Objectives: The classical renal manifestations of primary hyperparathyroidism (PHPT) are nephrolithiasis and nephrocalcinosis. The presence of renal stone categorizes PHPT as symptomatic variant. The clinical profile of PHPT has changed in past few decades with decreased prevalence of renal stone disease with the introduction of widespread routine biochemical screening in normal subjects. In developing countries, PHPT is still a late diagnosed disorder and most of the patients are symptomatic at presentation. Presence of renal stone in PHPT patients is an absolute indication of parathyroidectomy, hence it is important to identify renal involvement in PHPT. The objective of the study is to determine the rate of renal manifestations in patients of biochemically primary hyperparathyroidism and compared to control group. This retrospective review was performed to determine whether the rate of nephrolithiasis and nephrocalcinosis is still high in the patients who underwent dual phase 99mTc sestamibi scan for PHPT at National Institute of Nuclear Medicine and Allied Sciences (NINMAS) compared to those not affected by the disorder.

Patients and Methods: A total 149 patients (male 72 and female

77) and mean age $41 \pm 14.73$ years with PHPT were included in this study. All patients underwent dual phase $99 \mathrm{mTc}$ sestamibi parathyroid scan. Result of $99 \mathrm{mTc}$ sestamibi scan were divided into two groups. Group I represented positive scan and group II indicated negative scan respectively.Relevant clinical history, biochemical values including serum calcium level, serum parathormone (PTH) level and data on renal manifestations were recorded. The control group comprised of 650 subjects who had abdominal ultrasonography for various clinical conditions without any history of PHPT. Renal manifestations were compared between PHPT patients and the control group.

Results: Among 149 patients, scan was positive in 54(36.2\%) cases (group I) and scan was negative in $95(63.8 \%$ ) cases (group II). In group I, renal manifestations were present in 20 cases and absent in 34 cases. In group II, renal manifestations were present in 32 cases and were absent in 63 cases. Nephrolithiasis and nephrocalcinosis were present in $\mathbf{4 5 ( 3 0 . 2 \% )}$ ) and $\mathbf{7}(4.7 \%)$ cases respectively in study population compared to $8(1.23 \%)$ persons of control group of 650 subjects. Pearson's chi-square analysis showed that the difference in the rate of renal manifestations was significant $(p<0.001)$ between study population and control group. However, with in the study population the rate of renal manifestations between group $I$ and group II was not significantly different $(p=0.137)$.

Conclusion: This study showed eighteen fold increased renal manifestations in the patients with PHPT imaged for parathyroid gland compared to the subjects not affected by the disorder. Symptomatic variant of PHPT with renal manifestation was higher in this study compared to western countries. During parathyroid scanning in PHPT routine ultrasonographic evaluation of kidneys is necessary to exclude renal manifestation, even with negative parathyroid scan.

Key words: Sestamibi, Primary hyperparathroidiam (PTHP), Nephrocalcinosis.

\section{INTRODUCTION}

Primary hyperparathyroidism (PHPT) is a common endocrine disorder usually diagnosed by routine biochemical screening. PHPT is defined as hypercalcemia with increased or inappropriately secreted plasma parathyroid hormone $(\mathrm{PTH})$ by one or more abnormal parathyroid glands. It is most commonly seen after the age of 50 years, with women predominating by three to fourfold. PHPT is the most common cause of hypercalcemia in otherwise healthy patients (1). The clinical presentation of PHPT reflects the combined effects of hypercalcemia and 
increased PTH level. PHPT has been associated with a combination of symptoms including "painful bones, renal stones, abdominal groans, and psychic moans"

(2). The most common target of PHPT is kidney and skeleton.Over the past few decades the clinical profile of PHPT has changed dramatically due to widespread screening of serum calcium level in western countries. The routine biochemical screening was introduced in the 1970's. Early diagnosis of the disorder leads to significantly decreased prevalence of renal stone disease as well as skeletal manifestations, such as osteitis fibrosa cystica, osteoporosis, and bone fractures, have also reduced. PHPT has become a relatively common and quickly diagnosed disease and about $80 \%$ patients are asymptomatic. Sometimes patients may present with non specific symptoms such as fatigue mood disturbance and cognitive impairments (3-4).

However in developing countries, PHPT is still a late diagnosed disease and most of the patients are symptomatic at presentation. No reported data is available on the prevalence of renal stone diseases or nephrocalcinosis in PHPT patients of south Asian countries including Bangladesh. A number of patients with PHPT have been referred to NINMAS for dual phase $99 \mathrm{mTc}$ sestamibi scan to evaluated parathyroid abnormality. This retrospective review was performed to determine whether the rate of nephrolithiasis and nephrocalcinosisis still high in the patients of PHPT. Patients who underwent dual phase $99 \mathrm{mTc}$ sestamibi scan at NINMAS was compared to those not affected by the disorder. The objective of this study was to determine the rate of renal manifestations in patients of scan positive and scan negative patents who were biochemically PHPT and to compare with control group.

\section{PATIENTS AND METHODS}

This is a retrospective analysis of data of 149 patients (72 men and 77 women; mean age, $41 \pm 14.12$ years; age range, 16-86 years) with PHPT, underwent Tc99m sestamibi parathyroid scan during the period of January 2011 to November 2012 at NINMAS.The dual phase parathyroid imaging was conducted using NINMAS's standard protocols. After intravenous 99mTc sestamibi $20 \mathrm{mCi}$ (740-MBq) injection, anterior planar images of neck and upper chest were acquired with $256 \times 256$ matrix within 10 to 15 minutes (for early phase) and after 2 hours (for delayed phase), using a large field of view ECAM dual head Gamma camera equipped with a lowenergy, high resolution, parallel-hole collimator for image acquisition, up-to $700 \mathrm{Kcps}$. The energy windows were set with a photopeak at $140 \mathrm{keV}$ and the zoom factor 3.7. The scans were interpreted as positive for localization of parathyroid adenoma or hyperplasia when focal or diffuse area of increased uptake was present in the early phase and that persisted on delayed imaging. Presence of thyroid nodule on ultrasound at the region of $99 \mathrm{mTc}$ seatamibi uptake was excluded from the study.

The renal ultasonography findings of 149 PHPT patients were reviewed with advanced ultrasound machine at NINMAS in the same week of parathyroid scan. We collected the records and findings of a control group to assess the rate of renal calculi in patients not being evaluated for hyperparathyroidism. The control cohort consisted of abdominal ultrasonography scans obtained from same period for various reasons (e.g., upper abdominal pain, cholelithiasis, abnormal liver function studies) in 650 patients of 26 years old or older (212 men and 438 women; mean age, 45 years; age range, 26-80 years). Renal ultrasonography was performed using 3-7 MHz transducers in an attempt to image with the highest frequency transducer that would permit assessment of the entire kidney. The presence or absence of renal stones and nephrocalcinosis were noted. The findings in the reports were classified as positive or as negative for renal calculi or nephrocalcinosis. For definitive diagnosis in ultasonography, stones must show echogenicity (i.e., echo difference), posterior acoustic shadowing (5). 


\section{Statistical analysis:}

Pearson's chi-square test was used to determine the relationship between group I and group II of PHPT withthe presence of renal calculi compared to control group. A $p$ value of $<0.05$ was considered significant.

\section{RESULTS}

Among 149 patients male $(\mathrm{n}=72) 48 \%$, female $(\mathrm{n}=$ 77) $51 \%$ and mean age $41 \pm 14.73$ years were found. Normal serum calcium level were found in $57 \%(\mathrm{n}=$ 85) cases and higher than references in $43 \%(n=64)$ cases. Serum calcium level among the study population has shown in Table 1. On the basis of parathyroid hormone level, the study population was divided into three groups. Normal level was seen in $08(5.4 \%)$ cases; within 54-200 in 82(55\%) cases and more than 200 were seen in 54(36\%) cases. Parathyroid hormone level among the cases has shown in table 2. Result of $99 \mathrm{mTc}$ sestamibi parathyroid scan were divided into two groups, group I represented positive scan and group II indicated negative scan respectively and distribution of scan findings have shown in table 3 . In group I 54(36.2\%) patients had positive scan and group II 95(63.8\%) cases had negative scan (Table 3). Table 4 has shown association of scan findings and renal involvement. In group I, renal manifestations were present in 20 cases and absent in 34 cases. In group II, renal manifestations were present in 32 cases and were absent in 63 cases. Nephrolithiasis and nephrocalcinosis were present in $45(30.2 \%)$ and $7(4.7 \%)$ cases respectively among the study population of primary hyperparathyroidism compared to $8(1.23 \%)$ cases of control group of 650 subjects. Pearson's chisquare analysis showed that the difference in rate of renal manifestation was significant $(p<0.001)$ between study and control group (table 5). However, within the study population the rate of renal manifestations between group I and group II shown no significant statistical difference $(\mathrm{p}=0.137)$, shown in Table 4 . After performing the same review protocol as that performed in the patient group, definitive renal stones were confirmed in eight cases by doing ultrasonography. The final rate of renal calculi in the control group was $1.3 \%$.

Eighteen fold of increased rate of renal stones in patients with primary hyperparathyroidism compared with those not affected by the disorder was noted in this study. Chi-square analysis confirmed the significance of this finding. Pearson's chi-square value was $13.23(\mathrm{p}<0.0001)$.

Table 1: Showing serum calcium status among the study population $(n=149)$

\begin{tabular}{|l|c|c|}
\hline & Frequency & Percentage (\%) \\
\hline Normal & 86 & 57.7 \\
\hline High & 63 & 42.3 \\
\hline Total & 149 & 100.0 \\
\hline Mean \pm SD & $11.05 \pm 8.6$ & \\
Range & $6-12.50$ & \\
\hline
\end{tabular}

Table 2: The serum parathormone (PTH) level among study population $(n=149)$

\begin{tabular}{|l|c|c|}
\hline & Frequency & Percentage (\%) \\
\hline Normal & 8 & 5.5 \\
\hline $54-200$ & 82 & 55.0 \\
\hline$>200$ & 59 & 39.5 \\
\hline Total & 149 & 100 \\
\hline Mean \pm SD & $343.9 \pm 455.5$ & \\
Range & $(17.60-2249)$ & \\
\hline
\end{tabular}

Table 3: Distribution of $99 \mathrm{mTc}$ sestamibi parathyroid scan findings among study population.

\begin{tabular}{|l|l|l|}
\hline & Frequency & Percentage (\%) \\
\hline Group I (Scan positive) & 54 & 36.2 \\
\hline Group II (Scan negative) & 95 & 63.8 \\
\hline Total & 149 & 100.0 \\
\hline
\end{tabular}

Table 4: Renal involvement in group I and group II.

\begin{tabular}{|l|c|c|c|c|}
\hline & $\begin{array}{c}\text { No } \\
\text { involvement }\end{array}$ & $\begin{array}{c}\text { Renal } \\
\text { calculi }\end{array}$ & Nephrocalcinosis & P value \\
\hline Group I (Scan positive) & $34(35.2 \%)$ & $15(16.3 \%)$ & $5(2.5 \%)$ & \\
\hline $\begin{array}{l}\text { Group II (Scan } \\
\text { negative) }\end{array}$ & $63(61.8 \%)$ & $30(28.7 \%)$ & $2(4.5 \%)$ & $0.137^{\text {Is }}$ \\
\hline Total & $97(65.1 \%)$ & $45(30.2 \%)$ & $7(4.7 \%)$ & \\
\hline
\end{tabular}


Table 5: Renal involvement in case and control group.

\begin{tabular}{l|c|c|c}
\hline & $\begin{array}{c}\text { Control group } \\
(\mathrm{n}=650) \\
\text { No. }(\%)\end{array}$ & $\begin{array}{c}\text { Scan group } \\
(\mathrm{n}=149) \\
\text { No. }(\%)\end{array}$ & P value \\
\cline { 1 - 2 } $\begin{array}{l}\text { Renal manifestation } \\
\text { absent }\end{array}$ & $642(98.8)$ & $52(34.9)$ & \\
\cline { 1 - 3 } $\begin{array}{l}\text { Renal manifestation } \\
\text { prcsent }\end{array}$ & $8(1.2)$ & $97(65.1)$ & $<0.001 *$ \\
\hline Total & $650(100.0)$ & $149(100.0)$ & \\
\hline
\end{tabular}

\section{DISCUSSION}

The mean age of this study population was $41.7 \pm$ 14.1years; compared to 4th and 5th decade of life has been reported in other studies. No women predominance in the study population of PHPT was observed in this study; however other studies showed three to four fold women predominance (1). Serum calcium level was higher in $42.3 \%$ cases and increased PTH level was observed in $91.2 \%$ cases, showed similarity to other studies (6).

For more specific diagnosis and precise management, patients with PHPT need to exclude parathyroid adenoma or hyperplasia. 99mTc sestamibi scan has incredible importance for detection of number and location of adenoma. In this study positive parathyroid scan was observed in 54(36.2\%) cases and 95(63.8\%) patients showed negative scan for localization of parathyroid adenoma or hyperplasia. Renal calculi and nephrocalcinosis were evident in both groups, 20 cases in group I and 32 cases in group II.

In Western countries, the prevalence of renal stone disease has decreased from approximately from $80 \%$ to $7-20 \%$ in recent years (1). European data showed $25.4 \%$ rate of renal calcifications in PHPT (7) and another study reported only $19(7.0 \%)$ of the 271 patients with mild PHPT had renal stones, detected by the renal ultasonogram (8). In a systematic review on PHPT, in India, reported by various tertiary care institutes (344 PHPT cases) across the country showed the rate of renal disease in 36\% cases (9). Gopal et al reported renal calculi including nephrocalcinosis in $40.5 \%$ of the PHPT patients (10). Renal stone disease was present in $78 \%$ cases of symptomatic and in $35.5 \%$ asymptomatic PHPT patients has reported in another study by Cipriani et al (11). In this study the rate of renal stones and nephocalcinosis in PHPT patients was 52(34.8\%) and which was higher than the Western and European countries but similar to Indian review (9).

This study showed significant difference in the rate of renal manifestations between PHPT patient and control group. There is eighteen fold increased rate of renal stones in PHPT patients compared to the control subjects not affected by the disorder. Jane M Suhet et al in their study showed three fold increased prevalence of renal stone disease in asymptomatic PHPT patients compared to the control group (8).

According to the American National Institute of Health Consensus Panel renal stone disease in PHPT patient is an absolute indicator of parathyroid surgery (8). Routine evaluation of the kidneys is necessary for both scan positive and scan negative cases. In 1950s abdominal radiographs was used to detect the renal stone and that time large staghorn calculi filling the entire collecting system were typical in PHTP patients. Various radiologic techniques are available including abdominal radiography, CT, and MRI for kidney evaluation. These techniques are associated with radiation hazard and some are expensive. Ultrasonography is an effective, cheap, radiation free, very sensitive technique and can detect very small calculi of at least 5 millimeter size. It has been reported that in addition to a decrease in the prevalence of renal stone disease, the size of the detected renal stones has also decreased in recent years (12-13). In this study abdominal ultrasound was used for renal assessment.

\section{CONCLUSION}

This study showed eighteen fold increased rate of renal stone in the patients with PHPT imaged for parathyroid gland compared to the subjects not affected by the disorder. Symptomatic variant of PHPT with renal manifestation was higher in this study compared to western countries. During 
parathyroid scanning routine evaluation of kidneys using ultrasonography is necessary in PHPT patients to exclude renal manifestation, even with negative parathyroid scan.

\section{REFERENCES}

1. Silverberg SJ, Clarke BL, Peacock M, Bandeira F, Boutroy S, Cusano NE, Dempster D, Lewiecki EM, Liu JM, Minisola S, Rejnmark L, Silva BC, Walker MD, Bilezikian JP. Current issues in the presentation of asymptomatic primary hyperparathyroidism: proceedings of the Fourth International Workshop. J Clin Endocrinol Metab 2014; 99:3580-94.

2. Peacock M. Primary hyperparathyroidism and the kidney: biochemical and clinical spectrums. J Bone Miner Res 2002; 17:8794.

3. Lundgren E, Rastad J. Surgical Endocrinology. Philadelphia, Pa. Diagnosis, natural history and intervention in sporadic primary hyperparathyroidism. USA: Lippincott Williams and Wilkins 2001; 137-62.

4. S Fukuma, N Kurita, M Fukagawa. Impact of cinacalcetintroduction on MBD management: the MBD-5D study in Japan. Kidney Int Suppl 2013; 3:436-41.

5. Lee JY, Kim SH, Cho JY, Han D. Color and power Doppler twinkling artifacts from urinary stones: clinical observations and phantom studies. A J R 2001; 176:1441-45.
6. MasumaAkhter, Shamim M F Begum, Sadia Sultana, FaridulAlam. Primary Hyperparathyroidism: Comparison between Tc99msestamibi Parathyroid Scintigraphy and their Correlation with Serum Calcium, Parathyroid Hormone Levels. Bangladesh J Nucl Med 2013; 16(2):116-22.

7. Rejnmark L, Vestergaard P \& Mosekilde L. Nephrolithiasis and renal calcifications in primary hyperparathyroidism. Journal of Clinical Endocrinology and Metabolism 2011; 96: 2377- 85.

8. Jane M Suh, John J. Cronan, Jack M. Monchik. Primary hyperparathyroidism: Is there an increased prevalence of renal stone disease? Am J Roentgenol 2008;191:908-11.

9. Pradeep PV, Jayashree B, Mishra A, Mishra SK. Systematic review of primary hyperparathyroidism in India: The past, present, and the future trends. Int J Endocrinol 2011;(2011)921814:7.http://dx.doi.org/10.1155/2011/921814.

10. Gopal RA, Acharya SV, Bandgar T, Menon PS, Dalvi AN, Shah NS. Clinical profile of primary hyperparathyroidism from western India: A single center experience. J Post grad Med 2010; 56:79-84.

11. Cipriani C, Biamonte F, Costa AG, Zhang C, Biondi P, Diacinti D, Pepe J, Piemonte S, Scillitani A, Minisola S, Bilezikian JP Prevalence of kidney stones and vertebral fractures in primary hyperparathyroidism using imaging technology. J Clin Endocrinol Metab 2015; 100:1309-15.

12. Cassibba, Sara, Pellegrino, Micaela, Gianotti, Laura, Baffoni, Claudia, Baralis, Enrico. Silent renal stones in primary hyperparathyroidism: prevalence and clinical features. Endocrine Practice 2014; 20:1137-42.

13. Rao PN. Imaging for kidney stones. World J Urol 2004; 22:323-27. 